\title{
Clinical Pharmacy Profession and the Career Stepladder: Momentum to Change the Hierarchy
}

\author{
Asim Ahmed Elnour ${ }^{*}$ and Naama Al Kalbani ${ }^{2}$ \\ ${ }^{1}$ Pharmacology Department; College of Medicine and Health Sciences-UAE University, UAE \\ ${ }^{2}$ Senior Pharmacist, Tawam Hospital, Abu Dhabi Health Services-UAE
}

*Corresponding author: Asim Ahmed Elnour, Associate Professor, Pharmacology Department; College of Medicine and Health Sciences-UAE University. Tel: +97137022571/+971506734096 E-mail: assahura1962@uaeu.ac.ae

\section{Received Date: Sep 29, $2014 \quad$ Accepted Date: Oct 01, $2014 \quad$ Published Date: Oct 02, 2014}

Citation: Asim AE. Clinical Pharmacy Profession and the Career Stepladder: Momentum to Change the Hierarchy (2014) J Pharma Sci Drug Des 1(1): 1 .

\section{Introduction}

The clinical pharmacy profession is advancing rapidly with versatile changes, outstanding performances and numerous gains across the globe. We though to delve-deeper into the main issues that streamline the clinical pharmacy profession, strengthen its role and develop its ranking hierarchy.

Within the medicine field (Doctors), it has been well defined and distinguished that graduates advance in their career and climb the hierarchy ladder as they attain new certificates, boards, fellowships and so forth. This fact is not well defined in the pharmacy profession neither in its advanced discipline of clinical pharmacy. The ranking of clinical pharmacists as specialist, consultant and expert is fundamental to establish this hierarchy pyramid and move along the ladder steps of knowledge, practice, experience and finally expertise.

To be specialized in clinical pharmacy not only as Pharm D graduate (which resembles an undergraduate studies), it is imperative to get either board certification, higher diploma or Master of Science in clinical pharmacy. One could argue that Pharm-D holders (graduates) are well taught (per curriculum) as specialized clinical pharmacists (definitely), yet what next; they need more advanced specializing by attainment of certification and mastering degrees to further climb the ladder step-wise ${ }^{[1]}$.

Where you find yourself in this ladder, how you climb and what is your target is the pharos puzzle.

It is clearly distinct that holders of Doctor of Philosophy- in pharmacy (clinical pharmacy derived programs) are at the top of the ladder, particularly when the academic ranking is coupled with clinical experience (as the case with colleges of pharmacy attached to teaching hospitals). Therefore, they deserve the higher steps in this ladder within this professional hierarchy ${ }^{[2]}$.

It is a momentum for pharmacy licensing bodies, colleges, syndicates and associations to consider revising the pharmacy professional hierarchy. Licensing based on certification, experience gained by virtue of certification/boarding/graduate studies; should be considered to bring the career lineup not to turn the stepladder upside down.

We hereby, call for efforts to convey the everlasting hierarchy in medicine to pharmacy profession, whereby an intern clinical pharmacist receives training from an specialist or consultant clinical pharmacist (been awarded that license level $)^{[3]}$. The international pharmacy societies such as the European Society of Clinical Pharmacy and other leading pharmacy associations can strengthen the efforts towards shaping the clinical pharmacy hierarchy and shape the pharaoh pyramid in place.

The escalating number of clinical pharmacists worldwide deserves this momentum change, which will be reflected more in their role and better prosperous career.

Lastly, but not least "We must become the change we want to see", Mahatma Gandhi.

\section{References}

1.American College of Clinical Pharmacy Board of Regents, Maddux, M.S. Qualifications of pharmacists who provide direct patient care: perspectives on the need for residency training and board certification. (2013) Pharmacotherapy 33(8): 888-891.

2.American College of Clinical Pharmacy. A vision of pharmacy's future roles, responsibilities, and manpower needs in the United States. (2000) Pharmacotherapy 20(8): 991-1020.

3.American College of Clinical Pharmacy. The strategic plan of the American College of Clinical Pharmacy. ACCP. Rep. 2002; 21(10): S1-7.

Copy rights: (C)2014 Asim AE. This is an Open access article distributed under the terms of Creative Commons Attribution 4.0 International License. 